\title{
O que é a Inovação Social? Maleabilidade Conceitual e Implicações Práticas
}

\author{
Alcides Monteiro \\ Professor Associado com Agregação na Universidade de Beira Interior (UBI). Covilhã, Portugal. \\ Investigador no Centro de Investigação e Estudos de Sociologia (CIES-IUL), Lisboa, Portugal. \\ E-mail: alcidesmonteiro@ubi.pt, https:// orcid.org/0000-0002-4546-383X
}

\section{INTRODUÇÃO}

耳 ntre a ideia de que "a inovação social é uma área relativamente ¿jovem" (Mulgan, 2010:51) e o argumento de que se trata apenas de uma nova denominação para práticas antigas, nos últimos anos assistiuse a um crescente interesse no conceito e nas práticas de inovação social. No Brasil, e olhando para o campo científico, o debate tem sido rico e diversificado em ângulos de abordagem, desde a discussão do conceito e dos referentes teóricos que o suportam (Farfus e Rocha, 2007; Bignetti, 2011) até a sua ligação com a inovação tecnológica (Baumgarten, 2007, 2008; Caron, 2007) ou à conexão entre inovação social e desenvolvimento sustentável (Fachinelli, D’Arisbo e Maciel, 2014; Araújo e Cândido, 2015). Em Portugal, e no resto da Europa, a atenção prestada ao tema resulta em grande medida do ciclo de crise vivido e da procura de alternativas para a retração da intervenção providencial do Estado, para as dificuldades de financiamento enfrentadas pelo Terceiro Setor, assim como das tentativas para dinamizar o mercado do investimento social. Às publicações acadêmicas somam-se inúmeras iniciativas de divulgação (artigos nos media, seminários, apresentação de boas práticas, bootcamps) e formações especializadas, em que, em abono da verdade, nem sempre o tema é tratado com clarividência. A ambiguidade do debate e das soluções propostas deve-se sobretudo ao fato de uma mesma designação ser usada para identificar práticas muito distintas, suportadas por concepções sobre a inovação social que também não são coincidentes.

Na tentativa de contribuir para a clarificação do fenômeno (conceito e práticas) da inovação social, propomo-nos neste artigo começar por 
discutir o sentido e alcance do conceito de "inovação social". Nomeadamente, no que ele traduz de especificidade relativamente ao conceito mais amplo de inovação e ao mais restrito de inovação tecnológica. Mas, sobretudo, no modo como a própria definição de inovação social traduz hoje uma dualidade de perspectivas, conforme se olha o fenômeno como resposta a problemas sociais e a condições sociais, ou é primordialmente concebido no contexto da governança democrática e da vontade de transformação social. Tão mais pertinente quanto estas distinções não são apenas de índole teórica, mas repercutem no nível das opções de intervenção e do desenho de políticas públicas.

Porque julgamos ser possível integrar numa visão holística da inovação social elementos que até agora têm vindo a compor distintas acepções do conceito, avançamos na segunda parte do artigo para uma proposta de interpretação do conceito de inovação social, como composto por dois eixos fundamentais: um eixo instrumental (inovações setoriais + governança e externalidades) e um eixo político (learning communities + missão social e visão transformadora). Tal opção é suportada pelo pressuposto de que o investimento na inovação social será tão mais consistente e perene quanto for marcado por uma novidade no nível das soluções para os problemas sociais detectados, dos métodos e arranjos organizacionais colocados em prática, por sua vez subordinando as escolhas a princípios claros no que concerne à orientação socioeconômica e a finalidades de transformação social.

\section{INOVAÇÃO SOCIAL: DISTINTAS ACEPÇÕES PARA UM MESMO CONCEITO}

Apesar da aparente novidade da inovação social como um constructo ou conjunto de discursos, a história demonstra que os seres humanos têm repetidamente experimentado e alcançado mudanças sociais que são disruptivas e duráveis (Mulgan, 2010; McGowan eWestley, 2015). Florence Nightingale, pioneira na humanização do tratamento médico aos mais pobres e indigentes, assim como na organização do socorro a feridos de guerra (Guerra da Crimeia, 1853-1856) é amiúde citada como uma das primeiras líderes da inovação social no campo da assistência social. Ainda no século XIX e início do XX, a intervenção de sindicatos e cooperativas na criação de seguros coletivos contra a doença, de grupos de autoajuda ou de escolas populares, a par da ação filantrópica de alguns empresários, surgem como exemplos de inovação social que têm perdurado e se têm renovado ao longo do tempo. E já na década de 1970 do século passado, Muhammad 
Yunus, fundador do GrameenBank, introduziu a prática inédita do microcrédito, ao conceder empréstimos de baixo montante a famílias muito pobres de produtores rurais e principalmente a mulheres, para a criação do seu próprio negócio.

O reconhecimento do conceito específico e sua teorização são, todavia, muito mais recentes, ainda que rapidamente se tenham multiplicado as análises sobre a origem e evolução no uso do conceito de inovação social (Dandurand, 2005; Lévesque e Lajeunesse-Crevier, 2005; Bouchard, 2006; Farfus e Rocha, 2007; Mulgan et al., 2007; Mulgan, 2010; Bignetti, 2011; Rousselle, 2013; Brandsen et al., 2016). Deste ponto de vista conceitual, o carácter distintivo da inovação social começa por se afirmar a partir de um esforço de dissociação em relação à inovação tecnológica, para, depois, focar-se na clarificação dos seus contornos e principais características, segundo um exercício que se mantém inacabado e distante de consensos.

\section{Da inovação tecnológica à inovação social}

A base de ambos os conceitos é comum, chama-se "inovação". Por definição, as inovações representam uma ruptura em relação às rotinas, formas de pensar e de agir prevalecentes. E, como tal, são marcadas por um alto risco e incerteza no decurso da sua concretização. Joseph Schumpeter, referência essencial neste domínio, está na origem do paradigma que liga empreendedorismo e inovação. Para este autor, "os empreendedores são um tipo particular de agentes" (1926:116), que diferem na sua conduta do tipo de agente "racional-rotineiro" e que possuem qualidades excepcionais no âmbito da combinação de fatores de produção. A sua função é a de reformar ou revolucionar o padrão de produção, dando origem a novas combinações de fatores: criação de um novo produto; abertura de novos mercados; descoberta de uma nova fonte de matérias-primas ou produtos semiacabados; nova organização produtiva (Boutillier, 2010; Harrisson, 2012). Logo, a ação inovadora está no cerne do sucesso da dinâmica empreendedora, ainda que, como por vezes erroneamente se assumir, não se deva depreender do raciocínio de Schumpeter que todo o empreendedor é inovador e que as duas atividades se confundem. A verdade é que o contexto do empreendedorismo e da ação do empreendedor favorecem a inovação e a (re)organização que ela acarreta, tanto ao nível de inovações radicais (que entram em ruptura com o que existia até então e transcendem os limites tecnológicos que até o momento 
se impunham) como de inovações incrementais (as mais comuns, de natureza progressiva, uma série de mudanças no quadro dos parâmetros conhecidos ou a introdução num dado produto de características técnicas já utilizadas em produtos similares) (Lévesque, 2006).

Na perspectiva dos sociólogos, como é o nosso caso, é muito interessante registrar as afinidades identificadas (Swedberg, 2000; Martes, 2010) entre a teoria schumpeteriana do empreendedorismo e os contributos de Max Weber para a interpretação da relação entre "a ética protestante e o espírito do capitalismo". Antecipando-se à leitura feita por Schumpeter, já Weber considerava que o empreendedor é um tipo de pessoa dotada de carisma, ou seja, com a capacidade de cooptar o entusiasmo e a adesão de outros, abrindo assim espaço para liderar a mudança e a inovação. Por outro lado, ambos coincidem na ideia de que o empreendedor e a atitude empreendedora não resultam somente de características individuais, excepcionais, mas de um tempo e um contexto que as favorecem. Na circunstância, Weber analisa o modo como a ética protestante favoreceu o desenvolvimento de um ethos capitalista e de uma atitude positiva face ao espírito empreendedor e inovador. Por sua vez, o conceito de "empreendedor schumpeteriano" remete mais para o comportamento do que para o ator (Swedberg, 2000:17). Uma personalidade criativa e com boas ideias não é suficiente, o empreendedor deverá ter capacidade para ler o entorno em que se insere, reagir às resistências institucionais que se colocam e mobilizar os valores e os interesses que favorecem a mudança (Martes, 2010). Nomeadamente, as resistências e rigidezes impostas pela burocracia "racional-rotineira", tal como Weber já havia igualmente alertado. Por fim, assinale-se a apropriação pelo autor da linha metodológica weberiana, ao preocupar-se sobretudo em desenhar o tipo ideal conceitual de empreendedor, mais do que daí extrair consequências práticas no que concerne ao desenvolvimento e concretização do espírito empreendedor.

Como o próprio Schumpeter deixa antever, o termo "inovação" é amiúde formulado como quase equivalente ao de inovação tecnológica, pelo modo como esta surge como um conceito que pertence inicialmente ao mundo da empresa. Neste domínio, a inovação tecnológica tem vindo a ser associada a produtos e/ou procedimentos tecnologicamente novos ou melhorados, tal como se pode constatar na proposta feita no Manual de Oslo, publicado pela Organisation for Economic Co-operation and Development (OECD) em 1997: 
Uma inovação tecnológica de produto é a implantação/comercialização de um produto com características de desempenho melhoradas de modo a fornecer objetivamente ao consumidor serviços novos ou melhorados. Uma inovação do processo tecnológico é a implantação/adoção de métodos de produção ou comercialização novos ou significativamente melhorados. Pode incluir mudanças de equipamento, recursos humanos, métodos de trabalho ou uma combinação destes (OECD, 1997: 9).

A força do par "inovação" / "inovação tecnológica" e um certo reducionismo do primeiro conceito ao segundo justificam em parte as dificuldades constatadas na delimitação do conceito específico de inovação social. Também é verdade que aquelas e outras inovações, nomeadamente as organizacionais e institucionais (novos modos de gestão, nova organização do trabalho, novas regras), podem ser encaradas como tendo consequências sociais, ou seja, que nessa perspectiva "toda inovação é social" (Bouchard, 2006:1; Institut Godin, 2012:14). Todavia, para efeitos do que discutimos no presente artigo, interessa-nos sobretudo o modo como a circunscrição da "inovação social" tem sido empobrecida por uma "colagem" aos conceitos acima mencionados. A essa conexão se propicia o uso da expressão "tecnologia social" como "ideia de intervenção da ciência e tecnologia no sentido de resolver problemas sociais, a partir da expressão de necessidades e carências sociais e com o concurso das coletividades sociais" (Baumgarten, 2008:106), por organizações como a Fundação Banco do Brasil (FBB) ou o Instituto de Tecnologia Social (ITS BRASIL). No mesmo sentido, definições como a de

uma nova solução para um problema social, que é mais eficaz, eficiente, sustentável ou justa do que as soluções existentes, e pela qual o valor criado reverte principalmente para a sociedade como um todo ao invés de indivíduos em particular. (Phills Jr., Deiglmeier e Miller, 2008:36)

ou de que "as inovações sociais são sociais tanto nos seus fins como nos seus meios" (Mulgan, 2010:56) têm o mérito de serem "simples" e "incisivas" (idem). Mas, como pertinentemente observam Brandsen et al., o problema na definição da inovação social reside menos na "inovação" e muito mais no sentido a atribuir ao "social". Acrescentam ainda os autores que "... o que é necessário é um conceito de inovação social como um processo societal complexo, mais do que uma mera definição classificatória de uma ação ou produto" (Brandsenet et al., 2016:5). 
Já no que concerne à delimitação e identificação das suas principais características, um contributo analítico interessante está patente nas sucessivas propostas de tipologias, que ilustram devidamente a coexistência de diferentes concepções sobre a inovação social. Tanto mais interessante quanto igualmente nos alerta para a relação entre as categorias analíticas e as suas repercussões práticas, isto é, que as distinções não são apenas de índole teórica, mas têm repercussões no âmbito das opções de intervenção e do desenho de políticas públicas. As tipologias propostas, das quais citaremos aqui alguns modelos, distinguem-se sobretudo no número de acepções que contemplam. Ainda assim, prevalece o ponto comum de todas elas darem relevo ao modo como o espaço anglo-saxônico e o debate europeu tenderam a gerar duas interpretações diferentes da inovação social. Esta ênfase está presente, por exemplo, nas propostas analíticas feitas por Dennis Harrisson (2012), Tom Montgomery (2016) e pelo Institut Godin (2012).

Montgomery denomina-as, respectivamente, de "paradigma tecnocrático" e de "paradigma democrático" da inovação social. Segundo o autor, a construção discursiva da inovação social tecnocrática, ou neoliberal, está muito presente nos países de matriz anglo-saxônica, com destaque para os Estados Unidos e Reino Unido. Mas também tem sido privilegiada e suportada pelos órgãos da política europeia, nomeadamente pela Comissão Europeia. A agenda para a inovação social é gerida em termos de novos mercados e de competição, incluindo-se nela um projeto político de reengenharia do Estado e de "privatização suave" de serviços que eram do domínio do Estado-Providência (Kerstenetzky, 2012). Ao contrário, a concepção democrática da inovação social é essencialmente disruptiva e contra-hegemônica, concebendo aquela como um instrumento para politizar os espaços que os neoliberais tenderem a despolitizar, num desafio à distribuição vertical do poder na sociedade e sua substituição por alternativas horizontais promotoras da verdadeira participação comunitária. Os ecos dessa interpretação fazem-se sobretudo ouvir naqueles países e contextos societais em que as tradições da economia social, da economia solidária e dos desenvolvimentos de base local/ comunitária são mais fortes.

Por sua vez, o Institut Godin desenvolve uma proposta que assenta, em primeiro lugar, na dissociação entre "uma concepção centrada sobre a finalidade" e "uma concepção mais centrada sobre o processo". A primeira concepção, principalmente anglo-saxônica, cinde-se em duas abordagens: a abordagem institucional, que remete para a concepção 
da inovação social como instrumento de modernização das políticas públicas e se inscreve na perspectiva do new public management; e a abordagem empreendedora anglo-saxônica, que invoca a figura do empreendedor social e a finalidade social da sua ação. A segunda concepção tem sido sobretudo desenvolvida na Europa e no Quebec, e também contempla duas perspectivas: a perspectiva desenvolvida pelos investigadores da rede europeia EMES, baseada na figura da empresa social; a perspectiva institucionalista, insistindo sobre a dimensão coletiva e a vontade de "transformação social" inerente aos processos de inovação social, principalmente concebida no seio do Crises (Centre de Recherche sur les Innovations Sociales), em Quebec.

Por fim, fazemos referência à tripla tipologia apresentada por Richez-Battesti, Petrella e Vallade (2012), contemplando três acepções diferentes de inovação social, mas que os autores admitem entrecruzarem-se em várias dimensões: a inovação social como instrumento de modernização das políticas públicas; a visão empreendedora da inovação social; e a inovação social como sistema de inovação territorializado, inclusivo e participativo.

Das tipologias mencionadas sobressai a ideia comum de que a definição dainovação social traduzhoje uma dualidadedeperspectivas, conforme se olha o fenômeno como resposta a problemas sociais e a condições sociais, ou é primordialmente concebido no contexto da governança democrática e da vontade de transformação social (Andrew e Klein, 2010). Sem prejuízo das pontes que se podem entabular entre as duas visões, como adiante tentaremos demonstrar.

\section{Uma concepção utilitarista da inovação social}

A valorização da inovação social na sua capacidade para mobilizar recursos e resolver problemas, ou a orientação para a sua "finalidade social", têm sido particularmente sublinhadas por alguns dos autores mais influentes neste domínio. Entre eles, sobressai a contribuição de Geoff Mulgan, para quem a inovação social se traduz em

atividades e serviços inovadores, que são motivados pelo objetivo de ir ao encontro de uma necessidade social e que são predominantemente desenvolvidos e difundidos através de organizações cujos propósitos primordiais são sociais" (Mulgan, 2007:8). 
Na sua ótica, a inovação social torna-se um imperativo quando os problemas se agravam, os sistemas não funcionam e as instituições refletem mais os problemas passados do que os presentes, identificando um conjunto de áreas em que hoje o deficit de inovação social é mais flagrante: aumento da esperança de vida; crescente diversidade dos países e cidades; domínios de desigualdade social; crescente incidência de condições crónicas; problemas comportamentais; transições difíceis para a idade adulta; felicidade.

Da concepção adotada por Mulgan e outros autores (Phills Jr., Deiglmeier e Miller, 2008; Leadbeater e Meadway, 2008; Nilsson e Paddock, 2014), decorre um conjunto de características essenciais associadas ao conceito e, sobretudo, à concretização da inovação social. A primeira delas está contemplada na definição proposta por Phills Jr., Deiglmeier e Miller, segundo a qual

ao contrário dos termos empreendedorismo social e empresa social, a inovação social transcende setores, níveis de análise e métodos para descobrir processos - estratégias, táticas e teorias da mudança - que produzem impacto duradouro (2008:37).

Também Mulgan defende que, se "a inovação social costumava ser considerada reserva privada do terceiro sector" (2010:58), as perspectivas mais recentes enfatizam que a inovação social ocorre em todos os setores e que inovações específicas muitas vezes se movem entre setores à medida que evoluem. Ou seja, podem surgir no setor privado (finança ética ou responsabilidade social das empresas), no setor público (políticas ou modelos de serviço), no terceiro setor ou na família (que estão na gênese de movimentos sociais como o Slow Food ou dos direitos dos deficientes).

Em Portugal, uma das faces mais visíveis da interpenetração entre setores está bem patente no fato de serem, em variadas circunstâncias, fundações patrocinadas por grandes multinacionais e instituições financeiras que apoiam e financiam o surgimento de novas experiências socialmente inovadoras. Patrocinam negócios sociais, criam plataformas de crowdfunding, organizam bootcamps e concursos de ideias:

A missão da Fundação EDP [Eletricidade de Portugal] na área da inovação social passa por levar para a 'Economia Solidária' a noção e a prática do 
empreendedorismo social e da sustentabilidade, fundamentais para o desenvolvimento e para a sobrevivência das organizações sociais. (...) A Fundação EDP procura novas soluções para velhos problemas, afastando-se da lógica do apoio assistencialista e da filantropia do donativo. Atuar nas origens, procurar fórmulas, promover a colaboração entre todas as "Partes Interessadas", partilhar conhecimentos, disseminar ferramentas de gestão e de capacitação dos recursos humanos das organizações, fomentar uma cultura de resultados, procurar a sustentabilidade dos projetos - tudo isto é fundamental para quebrar os ciclos viciosos e de dependência. Mas não é suficiente. Eé aqui que entram as escolhas, ou seja, a determinação de seguir um rumo e dar eficácia aos recursos investidos (http:/ /www.fundacaoedp. $\mathrm{pt} /$ inovacao-social/missao/solucoes-que-geram-mudancas/47).

Retomando as ideias de Geoff Mulgan, este autor enfatiza três dimensões-chave no sucesso das inovações sociais: elas resultam normalmente em novas combinações ou híbridos de elementos já existentes, mais do que em elementos verdadeiramente novos; envolvem o cruzamento de barreiras organizacionais, setoriais ou disciplinares; dão origem a novas relações sociais entre stakeholders. E acrescenta-lhe, em co-autoria (Bacon et al., 2008), a proposta de um "modelo de inovação social local".

Figura 1

O modelo estratégico para a inovação social local

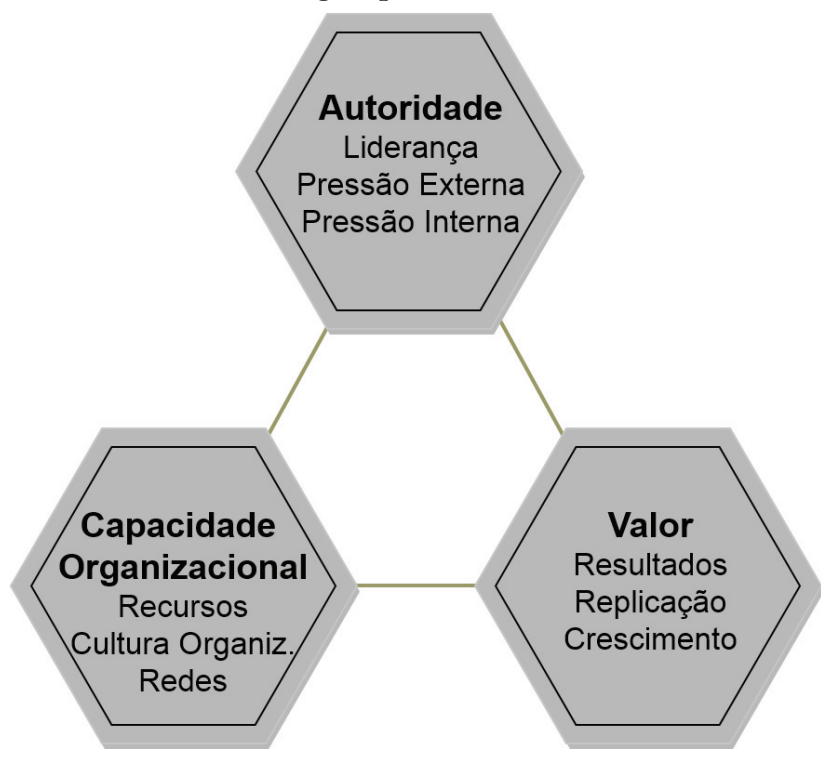

Fonte: Bacon et al. (2008:26). 
O modelo desenhado articula os fatores influentes na dinâmica de inovação: a autoridade, ou as pressões externas e internas que autorizam a mudança e que algumas vezes são refratadas através de uma liderança política; a capacidade organizacional, isto é, a demonstração de capacidades internas para operar a mudança e a sua disseminação (incluindo cultura, gestão e capacidade técnica); e o valor, traduzido no feedback que as lideranças recebem, tanto por via das redes externas como através do valor visível e benefícios públicos gerados, e que confere legitimidade à inovação implementada.

Uma terceira característica desta abordagem é a de que a inovação social faz apelo à figura do empreendedor social e à capacidade desses indivíduos para operarem a "destruição criadora" (Schumpeter, 1926) que conduz à mudança. $\mathrm{O}$ empreendedor social surge como $\mathrm{o}$ "timoneiro", ou o agente da mudança, capaz de abraçar uma missão social, reconhecer e procurar novas oportunidades para servir a essa missão, empenhar-se no processo de inovação, adaptação e aprendizagem, agir com ousadia e prestar contas com transparência em relação aos resultados obtidos (Dees, 2001; Harrisson, 2012). O empreendedor social, cuja ação visa conjugar eficácia econômica e impacto social, deverá distinguir-se do empreendedor comercial pela sua motivação de criar valor para a sociedade, e não de gerar valor para si próprio ou para a sua empresa. Contrariamente a este, cuja ação se focaliza sobre a apropriação de valor, o empreendedor social preocupa-se em gerar externalidades positivas, sobretudo nos domínios em que o Estado e o Mercado são ineficazes ou negligentes. Essas externalidades representam um benefício claramente superior para a sociedade do que o apropriado pelas partes em transação, e dirigem-se primordialmente a contextos localizados (populações isoladas, minorias étnicas, populações envelhecidas) ou aos segmentos mais desprotegidos da população (Santos, 2012).

Como corolário das opções anteriores, não será então de estranhar, e daqui decorre a quarta característica que pretendemos sublinhar, que esta concepção da inovação social tenda a valorizar a adaptação das lógicas de mercado à resolução de problemas sociais, também ela orientada para a eficiência dos processos e eficácia dos resultados (Phills Jr., Deiglmeier, e Miller, 2008). A perspectiva em causa considera como virtuosa a adoção de um "business-like behaviour" (Dart, 2004), refletido não apenas em objetivos de "produção de valor econômico e social", mas que se estende também às preocupações de eficiência 
e eficácia na provisão de bens e serviços, aos modelos de gestão organizacional implementados e à própria retórica, quando privilegia o uso de uma terminologia de negócios (Caron, 2007; Baumgarten, 2008). É imperativo reconhecer que esta via abre portas para soluções organizacionais e estratégicas até agora ainda não ensaiadas. Mas, ao mesmo tempo, aponta para um modelo de inovação social de "solidariedade fraca" (Amaro e Laville, 2016), que favorece a penetração do modelo mercantil no tratamento das questões da pobreza ou do ambiente, ao mesmo tempo que substitui o Estado Social nas suas obrigações públicas, e o desresponsabiliza.

Para concluir este ponto, importará sublinhar que esta perspectiva tem sido fortemente encorajada do ponto de vista político, nomeadamente por parte da OECD e da Comissão Europeia, ao ser adotada a definição de que

as inovações sociais são inovações que são sociais tanto nos seus fins como nos seus meios (...) Especificamente, definimos as inovações sociais como novas ideias (produtos, serviços e modelos), que simultaneamente promovem a resolução de necessidades sociais (de forma mais eficaz do que as alternativas), e criam novas relações sociais ou colaborações. Por outras palavras, são inovações que não só são boas para a sociedade como também reforçam a capacidade da sociedade para agir (Bureau of European Policy Advisers (BEPA), European Commission, 2011:9).

Acresce ainda o modo como a inovação social é incluída no leque de respostas desejáveis aos problemas sociais agravados com a crise econômica que a Europa vive desde 2008, na perspectiva de que "[a] inovação social não é uma panaceia, mas se incentivada e valorizada, ela pode aportar soluções imediatas para os problemas sociais prementes com que os cidadãos são confrontados." (idem:14).

\section{Inovação social e transformação social}

A proposta de uma visão alternativa para a inovação social parte sobretudo da Europa continental e do Quebec, muito particularmente em torno de autores que se expressam (predominantemente ou também) em língua francesa. O que não será seguramente apenas uma questão de coincidência, na medida em que esta ideia de inovação social tem sido amadurecida no prolongamento de uma forte tradição para en- 
carar (tanto ao nível analítico como pragmático) o desenvolvimento local e as iniciativas da economia social e solidária como vias para a coconstrução de políticas públicas, o desenvolvimento de uma economia plural ou ao ensaio de formas renovadas de democracia. A configuração do conceito repousa sobretudo na convicção de que o modelo de inovação social deve apostar numa "solidariedade forte" (Amaro e Laville, 2016), aspirante a ultrapassar a função meramente reparadora no domínio da economia, e substituindo-a por uma visão transformadora do modelo de desenvolvimento e das relações coletivas.

Marie J. Bouchard e Benoit Lévesque identificam-na como:

uma intervenção iniciada pelos atores sociais, para atender a uma aspiração, satisfazer uma necessidade, aportar uma solução ou beneficiar de uma oportunidade de ação, a fim de modificar as relações sociais, de transformar um quadro de ação ou de propor novas orientações culturais (2010: 5-6).

Acrescentam-lhe ainda a enumeração dos distintos tipos de inovação: relações de produção (implicação e participação dos trabalhadores, novas formas de organização do trabalho, criação de empresas autogestionárias, fundos de trabalhadores, empresas de inserção), relações de consumo (implicação e participação dos usuários, coprodução de serviços pessoais, coconstrução de novos programas e novas regras, consumo responsável, lazer e turismo responsáveis), relações entre empresas (cooperação e concorrência; interdependências não mercantis (externalidades), responsabilidade social corporativa), configuração espacial das relações sociais (novas formas de governança, desenvolvimento econômico comunitário). Por sua vez, segundo Yao Assogba:

É inovação social toda a iniciativa empreendida por parte de atores sociais num determinado contexto social com o objetivo de proporcionar respostas inéditas a um certo número de problemas sociais (exclusão social, pobreza, abandono escolar, etc.). Do ponto de vista sociológico, as inovações sociais apresentam as seguintes características principais: desafiam as dicotomias tradicionais como o as de "mercado e nãomercado", "produtor e não um produtor ou consumidor", "público e privado"; as inovações sociais buscamimplementar os meios adequados ao contexto societal; elas visam a coesão social e a solidariedade, baseiamse na democracia participativa, evitam a burocratização; as inovações 
sociais inspiram-se geralmente nos princípios fundamentais da economia social e da economia solidária (2007:10).

O ponto comum e fundador desta outra aproximação à inovação social é o de que a economia social e solidária ${ }^{1}$, assim como as dinâmicas de desenvolvimento local, se apresentam como importantes fatores, e motores, da inovação social (Lévesque, 2006; Klein et al., 2009). A "economia social e solidária" inscreve-se hoje nos modos de regulação emergentes (Bouchard, 2006), a par e muitas vezes como alternativa à regulação tutelar do Estado ou à regulação concorrencial do mercado, marcada pela particularidade de reconhecer explicitamente a dimensão social da economia. A economia social e solidária distingue-se pela procura de respostas coletivas para necessidades sociais não satisfeitas, estruturada a partir de múltiplas fontes de recursos e formas de provisão de bens e de serviços: mercantis, não mercantis (redistribuição) e não monetárias (dom e reciprocidade). Afirma-se ainda pela reposição no jogo econômico de pessoas que daí foram excluídas (microcrédito, comércio justo, gestão coletiva de terras e alojamentos) e pela valorização de regras e valores que potenciem a sua participação ativa. Entre elas, a adoção de formas organizativas de natureza associativa (sobretudo cooperativas, mutualidades e associações) e, no seio dessas organizações, pelos seguintes princípios: (1) finalidade de serviço aos membros ou à coletividade mais do que de lucro; (2) autonomia de gestão; (3) processos de decisão democrática; (4) primazia das pessoas e do trabalho sobre o capital na repartição dos excedentes. (Defourny e Develtere, 1997).

Muitas destas iniciativas escoram-se num território específico, estando na gênese ou sendo o corolário de dinâmicas de desenvolvimento local. Em locais e regiões penalizados por um tecido econômico frágil, em que ao envelhecimento da população se soma o agravamento dos problemas sociais e a incapacidade de os poderes públicos atenderem às necessidades, são as organizações do terceiro setor (associações, cooperativas, instituições particulares de solidariedade social...) que regularmente assumem a liderança de projetos de desenvolvimento econômico e social. O desenvolvimento local surge, assim, associado à prestação de serviços de proximidade, à diversificação das atividades econômicas, à valorização do patrimônio natural e sociocultural, à promoção da formação e da aprendizagem, entre tantos outros exemplos. As dinâmicas de intervenção adaptam-se às especificidades do território, vinculam as pessoas que aí residem e 
assumem a participação local, de uma forma democrática, como força motriz do desenvolvimento e do bem-estar (Monteiro, 2008, 2014; Squazzoni, 2008).

O encastramento da inovação social em dinâmicas locais ligadas à economia social e solidária e a interpretação daquelas como "laboratórios de inovação social", altera significativamente a configuração do conceito em análise quando comparado com a perspectiva anterior. Situamos as principais alterações em três domínios: na centralidade conferida ao processo (coletivo) que conduz à inovação; na importância que os fatores de contexto adquirem, particularmente o de "território"; e, ainda, na orientação da inovação social para valores que se confundem com a redefinição do paradigma de desenvolvimento e a transformação social.

Se a anterior abordagem se pautava por uma concepção utilitarista da inovação social, privilegiando-lhe a eficácia na resposta aos problemas sociais, na presente acepção é o processo (Hulgard e Ferrarini, 2010) que se torna o centro da atenção nas dinâmicas de inovação social. Concretamente, a qualificação de "socialmente inovadora" resulta em grande medida do modo como a identificação (ou revelação) das necessidades sociais resulta de uma dinâmica coletiva, partilhada entre profissionais e usuários. E, de igual modo, os objetivos de uma iniciativa são coletivamente definidos e se providencia conjuntamente o leque de soluções para a sua satisfação (Bignetti, 2011; Institut Godin, 2012). A finalidade da inovação não é definida previamente, resultando antes da capacidade para empreender coletivamente o trajeto entre a identificação das necessidades e a provisão de soluções. A inovação social suporá ainda a renovação dos arranjos institucionais e a criação de novos códigos de conduta, como resultado da modificação das relações sociais entre as partes envolvidas, ou stakeholders (setor público, organizações privadas lucrativas e não lucrativas, instituições de ensino, grupos de interesse, usuários etc.).

A inovação social é, neste quadro, pensada como um sistema territorializado. Do ponto de vista analítico, surge como desafiante a hipótese colocada por Jean-Marc Fontan, segundo a qual

... a dimensão social de toda a inovação remete para os mecanismos pelos quais se estabelece o encastramento da novidade num tecido territorial. Sem território não há sociabilidade e sem sociabilidade não há território! (2008:5). 
Em favor da sua validação, este e outros autores (Torjman e Leviten-Reid, 2003; Hillier, Moulaert e Nussbaumer, 2004; Andrew e Klein, 2010; Vallat, 2015) sublinham a importância da proximidade na facilitação das interações e na estruturação de redes locais, incluindo aquelas que combinam a participação dos usuários com a contribuição de atores oriundos de outras geografias e áreas de interesse (empresas, Estado, universidades, centros de investigação etc.). A territorialização das dinâmicas de inovação mobiliza setores-chave da comunidade em torno de prioridades locais, potencia a criação de espaços de cooperação entre os atores envolvidos, é crucial para a "tradução" e adaptação ao novo território de experiências já ensaiadas em outras geografias e contextos. De igual modo, ao aproximarem pessoas com diferentes origens, culturas e pontos de vista, para partilharem experiência e ideias, as dinâmicas geradas fomentam a aprendizagem comunitária (community learning) (Torjman e Leviten-Reid, 2003; Méndez, 2007), num tempo em que a capacidade para aprender e adaptar é crucial para a mudança social sustentada.

Finalmente, a inovação social é aqui interpretada como o resultado da combinação entre uma função reparadora e, num projeto mais ambicioso e muito mais complexo, a vontade de transformação social. À luz deste pressuposto, a inovação social só adquire verdadeiro valor (e distingue-se da invenção) quando se dissemina, se institucionaliza e se coloca ao serviço de mudanças permanentes. Isto é, contribui de forma efetiva para uma redefinição do paradigma de desenvolvimento.

\section{ESBOÇO DE UMA INTERPRETAÇÃO HOLÍSTICA DA INOVAÇÃO SOCIAL}

Não sendo inédita (Montgomery, 2016), a tentativa de conciliar os dois paradigmas em direção a uma interpretação holística da inovação social, que seja capaz de refletir o modo como tanto a dimensão funcionalista como a sua orientação sociopolítica são fundamentais para a concretização da inovação social, não tem sido particularmente abordada na conceitualização deste fenômeno. E, ainda assim, ela parece logicamente plausível, atendendo ao modo como as citadas acepções se focalizam sobre diferentes dimensões e elementos compositivos da dinâmica de inovação social. 
Os defensores da visão democrática e solidária da inovação social têm justificado a sua inconciliabilidade com uma abordagem mais tecnocrática da mesma argumentando que esta última, favorecedora da competição, da adoção de lógicas mercantis e de condutas de governança neoliberal, coloca em risco o caráter alternativo do terceiro setor e os seus valores fundamentais (Hillier, Moulaert e Nussbaumer, 2004). Ainda muito recentemente, num seminário dedicado precisamente ao tema da inovação social, ouvíamos expressões como as de que "as organizações do terceiro setor estão no mercado" ou "a economia social deve mimetizar o mercado, ainda que não lhe deva mimetizar as formas de transação". Ranci e Montagnini (2008) alertam para o fato de que a integração das organizações da sociedade civil num contexto mais competitivo e voltado para a marqueetização dos serviços sociais, onde ensaiada, tem significado igualmente uma tendência crescente para a inércia organizacional, maior imobilismo e perda das capacidades inovadoras: “É, portanto, um setor 'bloqueado' e estático, com pouco dinamismo e numa posição essencialmente defensiva" (2008:9).

Todavia, quando Bacon, Faizullah, Mulgan e Woodcraft (Bacon et al., 2008) enunciam três fatores críticos como determinantes das dinâmicas de inovação social, sendo essa vontade de mudar que resulta da consciência da ameaça ou da falha, a presença de capacidades internas de mudança (incluindo liderança e cultura), e o acesso a recursos externos (compreendendo pessoas, dinheiro, skills e redes), cabe perguntar: a economia social e solidária, assim como os promotores de projetos de desenvolvimento local, não reconhecem a importância destes fatores para a concretização dos resultados pretendidos, para a maximização das eficácias de gestão ou para a tão ambicionada institucionalização das soluções inovadoras? Não serão estas práticas compatíveis com a manutenção dos seus valores originais, se devidamente preservado o princípio de que a missão social "comanda" as opções de natureza econômica?

Já não merecerá seguramente idêntico consenso o modo como os citados autores consideram que esses fatores "... juntos explicam em grande medida como e porquê a inovação aconteceu" (Bacon et al., 2008:21).

Não encaramos como impensável a existência de uma mútua interpelação entre os dois modelos. Ela baseia-se em dois pressupostos 
simples, desde logo o de que cada um dos modelos encerra em si dimensões que são úteis à inovação social, quando observada a partir do prisma e das exigências do desenvolvimento local. Depois, de que cada um deles é incompleto na sua formulação própria. A inovação implica a acentuação de determinadas características já presentes no desenvolvimento local e na economia social e solidária. Mas também significa o desenvolvimento de novas capacidades e competências (skills), assim como é suposto encorajar a adoção de novas fórmulas organizacionais e de novas estratégias operacionais.

Partimos daqui para a proposta de um novo modelo estratégico para a inovação social local, que é distinto das duas concepções anteriores. Essa proposta é a de que se interprete o conceito de "inovação social", quando associado a uma estratégia de desenvolvimento local, como composto por dois eixos fundamentais: um eixo instrumental (inovações setoriais + governança e externalidades) e um eixo político (learning communities + missão social e visão transformadora).

Figura 2

Proposta de novo modelo estratégico para a inovação social local

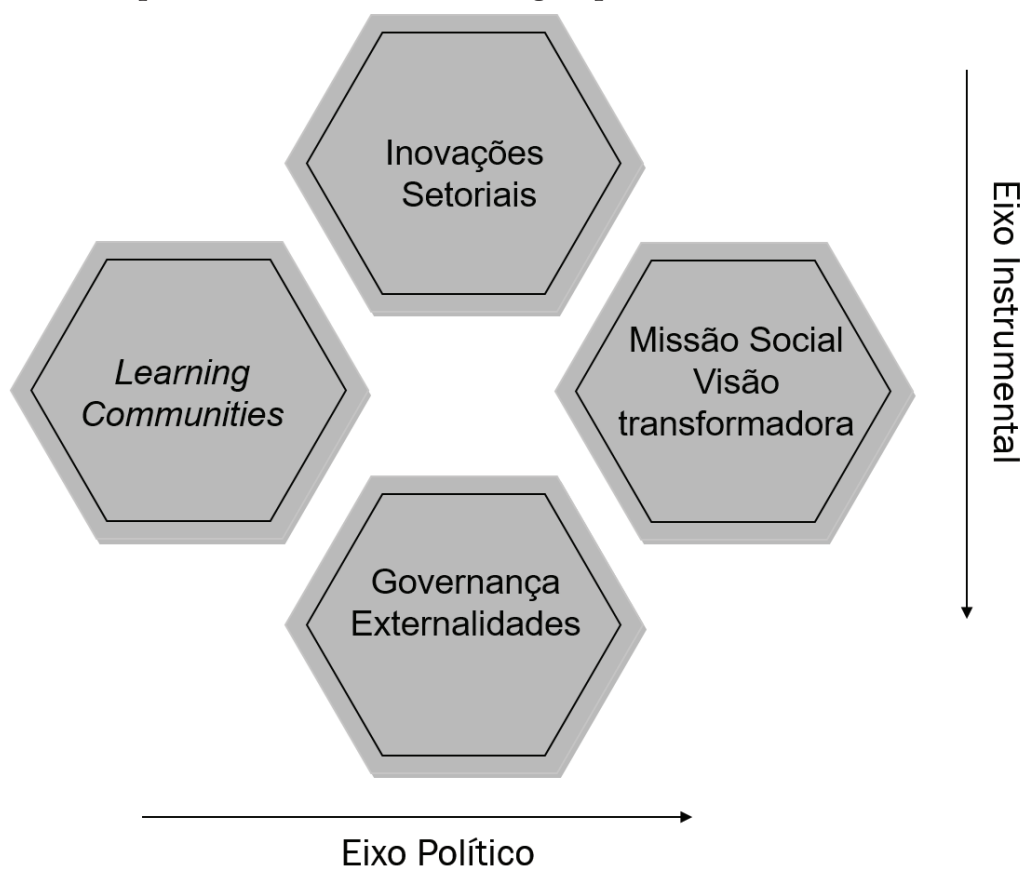

Fonte: Elaborado pelo próprio autor. 
No que concerne ao eixo instrumental da inovação social, e retomando uma ideia que é partilhada com as duas interpretações anteriores, a inovação social traduz-se antes do mais num conjunto de atividades e serviços inovadores, que são motivados pelo objetivo de ir ao encontro de uma necessidade social ainda não satisfeita. Entre vários casos que temos tido a oportunidade de acompanhar e/ou participar da sua avaliação, mencionaremos quatro exemplos ilustrativos dessa prioridade.

Como primeiro, o do trabalho desenvolvido pela Associação Sócio-Terapêutica de Almeida (Asta), uma associação para pessoas portadoras de deficiência, que junta a preocupação em proporcionar uma alternativa de vida válida e plena de sentido para pessoas necessitadas de cuidados especiais (os "companheiros"), com uma proposta de revitalização da pequena freguesia (cerca de 70 habitantes) em que está sediada. Para além de ser hoje a entidade empregadora mais significativa, a organização responde às necessidades do seu público-alvo através de uma abordagem integrada (pedagógica, terapêutica e social), ao mesmo tempo que oferece serviços sociais à coletividade, reaproveita o patrimônio edificado e entretanto abandonado, valoriza e aproveita os recursos endógenos (lã de ovelha, papel reciclado e cera de abelha), intervém na dinamização da vida cultural local, ou reforça "a consciência ecológica, social e humana" da comunidade (separação de lixos, compostagem, cozinha pedagógica) (Animar/ Adcmoura/ICE, 2013).

O segundo caso a citar é o da ação empreendida pelo GAF (Grupo Aprender em Festa) nos domínios da educação comunitária, da promoção da saúde, do desenvolvimento de competências, da inclusão social e da cidadania e desenvolvimento local. Especificamente, o caráter inovador da sua intervenção reside em colocar a experiência em "artes da comunicação" detida pelos membros do grupo ao serviço de dinâmicas de animação comunitária (entre elas, as que convergem para a valorização da "Festa"), em que as crianças assumem o papel de guias e se estimula a criatividade dos grupos locais. Entre outras, as "Festas da Saúde" e as "reuniões comunitárias" das aldeias, tornaram-se meios privilegiados para "... a identificação conjunta de necessidades e recursos, como base para a procura de uma mobilização sustentável das comunidades locais com vista a objetivos comuns" (Animar/Adcmoura/ICE, 2013:126).

O terceiro exemplo é o da Rede de Casas da Floresta, que identifica um conjunto de infraestruturas (Casas Temáticas) criadas no quadro 
de um programa para a inclusão e desenvolvimento, com o objetivo de proporcionar visibilidade a produtos selecionados como emblemáticos do território de referência (o mel, o cogumelo, o linho e o bombo), e que se transformou numa das forças motrizes do projeto, não só de promoção do patrimônio local mas também de estímulo empresarial e de envolvimento ativo das comunidades na procura de soluções para o (seu) desenvolvimento. Foram quatro as Casas criadas no Pinhal Interior do município do Fundão: a Casa do Mel, a Casa do Cogumelo, a Casa das Tecedeiras e a Casa do Bombo. Cada uma delas com a sua especificidade, todas convergem para a valorização das atividades econômicas das freguesias (estando cada Casa localizada na freguesia que mais se identifica com o produto em promoção), ao mesmo tempo que servem de suporte à dinamização de serviços de proximidade e implementação de projetos sociais.

O quarto exemplo remete à iniciativa promovida por uma instituição privada sem fins lucrativos, a ADCL (Associação de Desenvolvimento das Comunidades Locais), de instalação de um Centro Comunitário, ao serviço das populações locais e promotor da participação social. A partir desta estrutura, não só se disponibilizam serviços e recursos (mediateca/hemeroteca educativa, serviços de apoio psicológico, respostas culturais, informática etc.), como sobretudo se promove a participação para a integração social e para o desenvolvimento social: contribuir para a criação de condições que possibilitem às pessoas o exercício da sua cidadania; dinamizar e envolver os parceiros locais, potenciando os recursos existentes e fomentando a criação de novos recursos; desenvolver atividades dinamizadoras da vida social e cultural da comunidade (Animar/Adcmoura/ICE, 2013:120-121). Toda a ação da organização é baseada em cinco princípios: o princípio da endogenia; da promoção do desenvolvimento integrado; da interinstitucionalidade orgânica e da interdisciplinaridade metodológica; da articulação múltipla e o da investigação participante.

Para além das inovações setoriais que introduziram, estes quatro projetos orientam-se simultaneamente para uma reformatação das práticas de governança local. Por governança, entenda-se como:

... o quadro de interações estabelecidas entre a sociedade civil, o mercado e o poder público, transformadoras do modelo de administração da coisa pública, supondo que todas as categorias de stakeholders (cidadãos, terceiro sector, empresas, media, poder central e/ou autoridades locais) 
deveriam ter o poder de se influenciarem mutuamente nos processos de tomada de posição. (Monteiro, 2015:30).

Ou seja, que a vontade de inovar faz-se acompanhar da implementação de formas de gestão que sejam capazes de introduzir princípios democráticos na organização interna e no relacionamento com os stakeholders.

As práticas de governança não supõem a anulação da liderança. Pelo contrário, os exemplos acima citados ilustram claramente a importância de lideranças esclarecidas, capazes de organizacionalmente promoverem uma cultura de partilha e de coconstrução coletiva. Nos primeiro e terceiro casos ela está sobretudo identificada com modelos de liderança forte e legitimidade pela experiência, enquanto que a segunda e quarta intervenções se pautam por uma liderança partilhada e legitimidade democrática (Animar/Adcmoura/ICE, 2013; Monteiro, 2014). Dentre os vários estilos de liderança possíveis (tomando, como exemplo, a distinção feita por Kurt Lewin entre o estilo autocrático, o estilo democrático e o estilo "laissez-faire") (MENESES, 2010), aquele que mais se identifica com os princípios orientadores da ação do terceiro setor e os desafios do desenvolvimento local, é o estilo democrático. Na sua concretização, a liderança orienta-se para a codeterminação do interface entre as necessidades e as estratégias conducentes à sua resolução, envolve todos os agentes na tomada de decisões ("uma pessoa, um voto"), promove a coprodução de soluções, apoia-se em estratégias de comunicação abertas e bilaterais.

Por sua vez, a renovação das práticas de governança está igualmente associada à concretização do princípio da "parceria", quando entendido como uma fórmula de governar em rede, a partir de múltiplos centros, e ao abrigo do qual os diferentes stakeholders se coordenam e negociam a coconstrução e coprodução de soluções para os problemas identificados. A gestão governativa a partir de um conjunto de redes auto-organizadas tenderá a propiciar uma mais equilibrada distribuição do poder, maior autonomia de decisão nomeadamente em âmbito local, e o crescente envolvimento dos diferentes agentes nas dinâmicas de governança. Como poderá também induzir uma dinâmica de empowerment dos cidadãos, das cidadãs e das comunidades, ao facilitar-lhes a expressão das suas necessidades e o envolvimento ativo na procura de soluções que os/as beneficiem diretamente. 
O modelo estratégico para a inovação social local que aqui se propõe contempla ainda, no eixo instrumental, a valorização das externalidades. Usamos aqui o conceito de uma forma mais lata em relação ao que normalmente é adotado em economia [que, na circunstância, se reporta a efeitos positivos ou negativos sobre terceiros sem que estes tenham oportunidade de o impedir e sem que tenham a obrigação de os pagar ou o direito de ser indenizados (Nunes, 2015)], na perspectiva de efeitos gerados sobre o exterior, e que sejam visíveis a partir desse mesmo exterior. Entre eles, a produção de um impacto social que seja superior àquele gerado sobre os beneficiários diretos e demais agentes ativamente envolvidos na intervenção, a expansão das atividades, a inspiração de comunidades de apoio ou a articulação entre a prestação de serviços e a advocacia política em favor de causas sociais.

Uma das conclusões relevantes a extrair dos exemplos antes mencionados é a de que em todos eles se denota a capacidade de inovar internamente, tanto ao nível setorial como territorial e organizacional. Todavia, também é comum o fato de essa demonstração de vitalidade não se ter feito acompanhar de uma expansão da dinâmica de inovação para além do contexto em que foi originada. Ora, será pertinente reter as palavras de Grant e Crutchfield no remate de um estudo por eles conduzido:

A sabedoria convencional advoga que a expansão da inovação social começa pelo reforço das capacidades internas de gestão. Este estudo de 12 influentes organizações sem fins lucrativos mostra, contudo, que as verdadeiras mudanças sociais ocorrem quando as organizações saem das suas paredes e encontram modos criativos de ganhar o apoio de outros (2007:32).

Pelo que se coloca a seguinte questão: uma vez demonstrada a capacidade de experimentação e de modelização de processos inovadores, como difundir a uma escala maior uma inovação que deu provas sobre um território específico?

Na sua proposta de modelo estratégico para a inovação social local (ver Figura 1), Bacon, Faizullah, Mulgan e Woodcraft (Bacon et al., 2008) lembram que a maximização do potencial inovador (fator "valor") está associada a resultados, replicação e crescimento. Para além de outros, os resultados mais relevantes são aqueles que se traduzem em impacto social: 


\begin{abstract}
Oimpacto social consiste no conjunto de consequências (evoluções, inflexões, mudanças, ruturas) das atividades de uma organização, tanto sobre os stakeholders externos (beneficiários, usuários, clientes) diretos ou indiretos do seu território e internos (funcionários, voluntários), e na sociedade em geral. No setor da economia social, ele resulta da capacidade da organização (ou de um grupo de organizações) para antecipar necessidades não ou mal atendidas e responder-lhes através das suas missões de prevenção, reparação ou compensação. Isso traduz-se em termos de bem-estar individual, comportamentos, capacidades, práticas sectoriais, inovações sociais ou decisões públicas (Sibieude e Claverie, 2011:8).
\end{abstract}

Não basta gerá-lo, é preciso ter consciência clara da sua natureza e dimensão, pelo que hoje as organizações estão cada vez mais pressionadas para promoverem a avaliação desse mesmo impacto social e consequente publicização dos seus resultados.

Por outro lado, a demonstração de resultados visíveis e mensuráveis é argumento determinante para o possível crescimento (mobilização de recursos adicionais e apoios externos) e replicação (expansão e mudança de escala) da inovação social. O valor criado e o benefício público visivelmente gerados são determinantes na manutenção do momentum e legitimação da intervenção. No que concerne ao primeiro, a mobilização de recursos e apoios ocorrerá através do acesso a novos financiamentos, da criação de colaborações, da mobilização do(s) público(s) ou da adesão a causas sociais promotoras da mudança (Grant e Crutchfield, 2007; Bacon et al., 2008). No que respeita a estratégias de expansão e mudança de escala, estas podem traduzir-se no aprofundamento e/ou diversificação da ação já empreendida, da sua difusão geográfica ou da duplicação do projeto original. Logo, por uma ação que exige o reforço das capacidades internas, a associação a outros parceiros ou a inspiração de novas estruturas de intervenção (fazer fazer) (André, Gheerbrant e Pache, 2014; SGMAP, 2015).

Para todas estas estratégias são não só determinantes liderança e capacidade planificadora, como exigem novas competências técnicas e o domínio de novas tecnologias. As organizações de nova geração têm-se mostrado muito ativas nas redes sociais, na conquista de parceiros oriundos do mercado convencional, na implementação de estratégias de marketing social, de crowdfunding ou de mainstreaming. O mesmo não poderá ser dito relativamente às organizações mais tradicionais, para as quais a externalização se constitui como um desafio maior. 
O modelo de inovação social que propomos articula o eixo instrumental da intervenção com um outro eixo de maior amplitude programática, o eixo político. A aproximação do conceito de inovação social aos de economia social e solidária e de desenvolvimento local favorece tal interpretação:

Falando de inovação social, de mudanças nas relações sociais, nas relações interpessoais, trata-se de colocar a questão ao nível do viver em conjunto, ao nível político. A este respeito, o termo de economia solidária poderia sugerir que a ênfase será sobre o econômico, quando o essencial é da ordem do político, da capacidade conferida a cada um de participar na evolução da sociedade, para participar ainda que modestamente na construção de seu ambiente. (Roustang, 2003:2).

O eixo político confere relevo à dimensão democrática da inovação social e a desafia a ser parte de uma mudança sistêmica.

Uma das premissas da inovação social é a de que ela obedece antes de mais nada a uma missão social, que deve ser clara, determinada e conhecida. Por missão social, entenda-se o encastramento da inovação numa dinâmica de mudança socialmente relevante, quer se trate da satisfação de necessidades sociais emergentes, da criação de valor de uso socialmente útil, ou da sua implantação num tecido territorial particular. Neste ponto, entendemos que o maior desafio que se coloca às experiências de inovação social não é tanto o de enunciar a utilidade social da intervenção, até porque em última análise "toda a economia é social". Mas, sim, o de se comprometer com princípios e prioridades estratégicas que garantem, perante a coexistência entre a dimensão social e a dimensão econômica das iniciativas, a inequívoca "função de comando" da missão social sobre o valor de troca (valor de mercado) gerado.

Ilustrando com alguns exemplos que genericamente são identificados como próximos da denominada "economia colaborativa" e alternativos à economia capitalista convencional, o que poderá distinguir as iniciativas ligadas aos sistemas locais de trocas, às moedas locais ou à agricultura comunitária, dessas outras como as plataformas comunitárias de reserva de serviços (tais como a Airbnb ou a Uber) ou o empréstimo social (crowdfunding e outros)? Se os dois últimos exemplos se traduzem em efeitos sociais, nomeadamente no que concerne ao acesso, via prestação ou aquisição, a certos serviços por 
parte de pessoas com mais baixos rendimentos, tal não significa que o valor econômico deixe de ser encarado como a sua principal força motriz (Emin, 2016). De igual modo, se Mark Zuckerberg, fundador da rede social Facebook, afirmava em 2012 numa carta aberta dirigida a potenciais investidores, que "Facebook não foi originalmente criada para ser uma companhia. Foi construída para concretizar uma missão social - a de tornar o mundo mais aberto e conectado" e, ainda, que "nós não construímos serviços para ganhar dinheiro, nós fazemos dinheiro para construir melhores serviços", dificilmente se poderá recusar que o desenvolvimento da mencionada rede social esteja hoje essencialmente orientado para a sua eficiência econômica.

Distintas prioridades estão na gênese dos sistemas locais de trocas, das moedas locais ou da agricultura comunitária. Entre elas, o compromisso com os valores do desenvolvimento local, da partilha social, do empowerment e da participação democrática. A dimensão econômica dos projetos é um garante essencial da perenidade dos projetos e da possibilidade de continuarem inovando. Mas projetos desta natureza só manterão a sua razão de existir como alternativas inovadoras, enquanto assegurarem que a sua forma de satisfazer as necessidades sociais repousa sobre uma ética social e inverte o sentido do impulso criador (substituição de uma lógica top-down por uma lógica bottom-up), assim como incorpora a promoção de relações sociais de natureza colaborativa e a (re)apropriação do poder por parte dos indivíduos.

Uma das externalidades possíveis deste esforço colaborativo será a do envolvimento das iniciativas inovadoras na ativação de learning communities. Ou seja, que a inovação social seja também oportunidade e espaço de aprendizagem coletiva.

Entre as várias mudanças que a globalização neoliberal introduziu, uma delas é a da crescente incerteza das escolhas, tanto individuais como coletivas. Tal como refere Ulrich Beck (1986), a incerteza e a precariedade instalaram-se no seio da ordem social, genericamente considerada e na vida de cada um/a de nós. O indivíduo é cada vez mais pressionado para, num contexto de imprevisibilidade sobre os resultados das decisões individuais, fazer opções de vida que sejam autônomas e únicas e em seguida assumir responsavelmente as consequências das mesmas. Assim se pronunciam os valores da autonomia e da responsabilidade individual, no quadro das sociedades capitalistas e neoliberais. Idêntica indecisão se faz sentir ao nível das comunidades 
locais, particularmente quando pressionadas por contextos de desfavorecimento e o desafio a procurarem as suas próprias soluções.

Como tal, algures entre o ideário neoliberal de que estamos livres mas também isolados perante os problemas, e a determinação externa e estatista de um destino para o qual não contribuímos, as iniciativas socialmente inovadoras podem constituir-se como microespaços públicos de conhecimento e de deliberação, tirando partido do learning-by-doing, do learning-by-using (Lévesque e Lajeunesse-Crevier, 2005) e do learning-by-debating. Do ponto de vista processual, a inovação social está regularmente associada a reestruturações organizacionais, tão mais proficientes quanto os intervenientes nas mesmas forem capazes de mobilizar distintos quadros cognitivos e culturas, partilharem saberes e comunicarem horizontalmente.

Por outro lado, concebemos a inovação social como se refletindo também numa mudança das relações sociais, incluindo as relações de poder. A incorporação do princípio do empowerment significa que os projetos sociais se abrem à participação direta dos habitantes do bairro ou da comunidade na revelação das suas necessidades e coprodução das respostas a dar para o desenvolvimento do seu território. Não os encerrar num estatuto de consumidores passivos, mas reconhecê-los como cidadãos responsáveis e ativos no processo de decisão relativo ao seu desenvolvimento e ao desenvolvimento das suas comunidades (Monteiro, 2011). O que, do ponto de vista da sua concretização prática, exige investimento (via formação ou atividades de desenvolvimento) em competências que potenciam o empowerment dos intervenientes e a transformação dos habitantes em atores políticos. Entre outras: (auto) reflexividade e autonomia de decisão; capacidade de identificação de problemas, estratégias e recursos mobilizáveis; capacidade negocial; compreensão das lógicas de concertação e trabalho em equipe. Depois, que essa responsabilidade não seja imputada isoladamente às populações, sob eventual coordenação de equipes técnicas, mas comprometa todos os stakeholders (organizações da sociedade civil, poderes públicos, empresários, representantes da comunidade, grupos desfavorecidos...) num esforço cooperativo, no pressuposto de que todas as partes extraem aprendizagem do trabalho conjunto e reforçam o seu compromisso para com os resultados.

Tanto a qualificação da missão social como a incorporação de dinâmicas de aprendizagem comunitária são elementos essenciais para 
a consolidação do eixo político da inovação social. Este reporta-se a uma visão transformadora da sociedade. Quando inscrita em processos de desenvolvimento local e na promoção da economia social e solidária, a inovação social concorre para o questionamento da exclusividade conferida às lógicas mercantis no desenvolvimento econômico (Bouchard, 2006). Em alternativa, insere-se no movimento que pugna pela afirmação de uma economia plural, em termos de atores e de recursos, mercantis, não mercantis e não monetários. Por outro lado, participa de um processo de reencastramento da economia num projeto político democrático, a partir do momento em que favorece a emergência de formas de regulação partenarial, em alternância com a regulação tutelar e concorrencial. A adoção de novas práticas de governança, através do duplo movimento de participação alargada dos agentes (públicos e privados, com particular incidência sobre as comunidades locais) e da coconstrução da procura e da oferta, abre portas à ligação da economia plural a uma democracia plural (Amaro e Laville, 2016). E contribui, ainda, para ultrapassar uma das mais flagrantes incongruências da democracia atual: por um lado, erguem-se as vozes que denunciam a escassez da participação pública e o desinteresse dos cidadãos e cidadãs; por outro, mantêm-se as barreiras que impedem esses cidadãos e essas cidadãs de participarem ativamente na vida da sua comunidade e do seu país. Finalmente, a inovação social produz-se muitas vezes em associação com movimentos ecologistas, de protesto político antiglobalização, de resistência por parte de populações indígenas ou de afirmação cultural alternativa, na defesa de que "outro mundo é possível" (Moulaert et al., 2005).

\section{CONSIDERAÇÕES FINAIS}

À semelhança de outros domínios da intervenção social, o desenvolvimento local e as iniciativas associadas à promoção da economia social e solidária são hoje palco de múltiplas experiências de inovação social. Um palco privilegiado, no qual se cruzam intervenções que oscilam entre a orientação para a satisfação de necessidades sociais emergentes pela via dos ganhos em matéria de eficiência e eficácia, igualmente suportados por renovados modelos organizacionais, e visões que concebem a inovação social como uma sequência de "pequenas revoluções" ao serviço de processos capazes de induzirem a transformação social e a redefinição do paradigma societal. Entre lógicas adaptativas e ambições transformadoras, a inovação social aporta riqueza e diversidade à intervenção social, mas também gera 
acesos. Mas também porque o poder político central tem alienado parte das suas responsabilidades ao nível das políticas redistributivas e prestação de serviços sociais básicos, com visível prejuízo para as comunidades do interior do país. Logo, o desenvolvimento local incorpora cada vez mais o exercício de gerir recursos escassos, de forma inovadora, face a necessidades crescentes e "ainda não", ou "já não", percebidas como importantes tanto pelo Estado como pelo mercado (Moulaert et al., 2005).

A reivindicação do papel forte do Estado Social e da alternativa ao capitalismo a ser suportada pela economia social e solidária, não pode ser argumento para descurar a resposta imediata às pessoas e suas necessidades. Do mesmo modo que não será aceitável que a provisão de serviços "dispense" a reivindicação política e se remeta a uma interpretação tecnocrática da inovação social. Pelo que julgamos fazer sentido conceber a inovação social como o resultado desejável do cruzamento virtuoso entre provisão de serviço e compromisso político. Isto é, que a inovação social seja promotora de fórmulas mais eficientes e eficazes de resolução das necessidades sociais emergentes, em simultâneo com a concretização de princípios que desde há muito integram o ADN daquelas organizações sociais que ambicionam ser alternativa à via estreita do paradigma dominante.

Por último, não descartamos a possibilidade de a configuração do modelo estratégico para a inovação social local proposta neste artigo ser (ainda) provisória, em construção e carente de revisão. Serve, ainda assim, para incitar ao debate e a uma reflexão que tenda a sofisticá-lo do ponto de vista analítico e das orientações práticas que possa produzir.

(Recebido para publicação em 12 de janeiro de 2017)

(Reapresentado em 16 de maio de 2018)

(Aprovado para publicação em 14 de fevereiro de 2019)

Nota

1. Não iremos neste artigo operar uma distinção analítica entre "economia social" e "economia solidária", optando antes por valorizar as dimensões que são comuns às duas abordagens. Embora reconheçamos valor à diferenciação que alguns autores fazem entre as duas realidades (Monteiro, 2004:106-115) 


\section{REFERÊNCIAS BIBLIOGRÁFICAS}

AMARO, Rogério R.; LAVILLE, Jean-Louis. (2016), "Social innovation in Europe: what relation with solidarity economy?" RIPESS Europe.

ANIMAR/ADCMOURA/ICE. (2013), ASAS - Aldeias sustentáveis e activas - programa mínimo de revitalização de aldeia. Edição de Autor.

ANDRÉ, Kévin; GHEERBRANT, Clémentine; PACHE, Anne-Claire. (2014), Changer d'echelle - manuel pour maximiser l'impact des enterprises sociales. Institut de l'Innovation et de l'Entrepreneuriat Social - ESSEC Business School.

ANDREW, Caroline; KLEIN, Juan-Luis. (2010), Social innovation: what is it and why is it important to understand it better. Québec, CRISES.

ARAÚJO, Otávio; CÂNDIDO, Gesinaldo. (2015), “Tecnologia social e inovação social: interação indutora do desenvolvimento sustentável nos territórios rurais". Espacios, v. 36, n. 13. Disponível em revistaespacios.com/a15v36n13/15361301.html. Acessado em 25 de abril de 2018.

ASSOGBA, Yao. (2007), Innovation sociale et communauté: une relecture à partir des sociologues classiques. Québec, Alliance de recherche université-communauté.

BACON, Nicola et al. (2008), Transformers - How local areas innovate to address changing social needs. London, NESTA.

BAUMGARTEN, Maíra. (2007), “C\&T na semiperiferia e inovação social: desigualdades, excelência e competitividade". in: M. L. Maciel e S. Albagli (orgs.), Informação e Desenvolvimento: conhecimento, inovação e apropriação social. Brasília, UNESCO/IBICT, pp. 271-295.

BAUMGARTEN, Maíra. (2008), "Ciência, tecnologia e desenvolvimento - redes e inovação social". Parcerias Estratégicas, n. 26, pp. 101-123.

BECK, Ulrich. (1986), Risk society. Towards a new modernity. London, Sage.

BIGNETTI, Luiz P. (2011), “As inovações sociais: uma incursão por ideias, tendências e focos de pesquisa”. Ciências Sociais Unisinos, v. 47, n. 1, janeiro/abril, pp. 3-14.

BOUCHARD, Marie J. (2006), L'innovation sociale en économie sociale. Chaire de recherche du Canada en économie sociale. Québec, Université de Montréal.

; e LEVESQUE, Benoît. (2010), Économie sociale et innovation: l'approche de la régulation, au coeur de la construction québécoise de l'économie sociale. Québec, CRISES.

BOUTILLIER, Sophie. (2010), “Comment l'entrepreneur peut-il ne pas être social?". in: S. Boutillier; S. Allemand (dir), Économie sociale et solidaire - nouvelles trajectoires d'innovations. Paris, L'Harmattan, pp. 107-125.

BRANDSEN, Taco et al. (2016), "Social innovation: a sympathetic and critical interpretation". in: T. Brandsen et al. (eds.), Social innovations in the urban context. Cham, Springer International Publishing, pp. 3-18.

BEPA (Bureau of European Policy Advisers) e European Commission. (2011), Empowering people, driving change, social innovation in the European Union. Luxembourg, EUR-OP. 


\section{Alcides Monteiro}

CARON, Antoninho. (2007), "Inovação Social e o papel da indústria". in: D. Farfus; M. C. S. Rocha (coords.), Inovações Sociais. Curitiba, FIEP - Federação das Industrias do Estado do Paraná, pp. 85-116.

DANDURAND, Louise. (2005), "Réflexion autour du concept d'innovation sociale, approche historique et comparative". Revue Française d'Administration Publique, n. 115, pp. 377-382.

DART, Ray. (2004), "Being 'business-like' in a nonprofit organization: a grounded and inductive typology". Nonprofit and Voluntary Sector Quarterly, v. 33, n. 2, pp. 290-310.

DEES, Gregory. (2001), O significado do 'empreendedorismo social'. Disponível em http:// www4.fe.uc.pt/cec/significadoempreendedor.pdf.

DEFOURNY, Jacques; DEVELTERE, Patrick. (1997), Jalons pour une clarification des débats sur l'économie sociale. Luxembourg, ADA (Appui au Développement Autonome).

EMIN, Sandrine. (2016), Innovation sociale, un détour par les comuns. Communication au RIUESS 2016 - XVI Rencontres durés au Inter-Universitaire de l'Economie Sociale et Solidaire, Montpellier, 25-27 de maio.

FACHINELLI, Ana C.; D'ARISBO, Anelise; MACIEL, Erick de M. (2014), “A importância da inovação social e da economia criativa como indutores para o desenvolvimento sustentável". International Journal of Knowledge Engineering and Management, v. 3, n. 5, pp. 276-293.

FARFUS, Daniele; ROCHA, Maria C. S. (2007), "Inovação Social: um conceito em construção". in: D. Farfus e M. C. S. Rocha, (coord.), Inovações Sociais. Curitiba, FIEP - Federação das Indústrias do Estado do Paraná, pp. 13-34.

FONTAN, Jean-Marc. (2008), “Développement territorial et innovation sociale: l'apport polanyien". Revue Interventions économiques [online], n. 38. Disponível em http:// interventionseconomiques.revues.org/369. Acessado em 20 de julho de 2016.

GRANT, Heather M.; CRUTCHFIELD, Leslie R. (2007), "Creating high impact nonprofits”. Stanford Social Innovation Review, v. 5, n. 4, pp. 32-41.

HARRISSON, Dennis. (2012), “L'innovation sociale et l'entrepreneur schumpétérien: deux lectures théoriques". Revue Interventions économiques [online], n. 45. Disponível em http://interventionseconomiques.revues.org/1710. Acessado em 20 de julho de 2016.

HILLIER, Jean; MOULAERT, Frank; NUSSBAUMER, Jacques. (2004), “Trois essais sur le rôle de l'innovation sociale dans le développement territorial". Géographie, Economie, Société, n. 6, pp. 129-152.

HULGARD, Lars; FERRARINI, Adriane V. (2010), “Inovação Social: rumo a uma mudança experimental na política pública?" Ciências Sociais Unisinos, v. 46, n. 3, pp. 256-263.

INSTITUT GODIN. (2012), L'innovation sociale en pratiques solidaires. Amiens, Institut JeanBaptiste Godin.

PHILLS Jr., James A.; DEIGLMEIER, Kriss; MILLER, Dale T. (2008), "Rediscovering social innovation". Stanford Social Innovation Review, v. 6, n. 4,, 6.4, pp. 34-43.

KERSTENETZKY, Celia Lessa. (2012), "Sobre a 'crise' do Estado de Bem-Estar: retração, transformação fáustica ou o quê?". Dados - Revista de Ciências Sociais, v. 55, n. 2, pp. 447-485.

KLEIN, Juan-Luis et al. (2009), L'innovation sociale au Québec: un système d'innovation fondé sur la concertation. Québec: CRISES.

DADOS, Rio de Janeiro, vol.62(2):e20170009, 2019. 
LEADBEATER, Charles; MEADWAY, James. (2008), Attacking the recession. How innovation can. Fight the Downturn. London: NESTA.

LÉVESQUE, Benoît; LAJEUNESSE-CREVIER, François. (2005), Innovations et transformations sociales dans le développement économique et le développement social: approches théoriques et politiques publiques. Québec, CRISES.

LÉVESQUE, Benoît. (2006), Le potentiel d'innovation et de transformation de l'économie sociale: quelques éléments de problématique. Québec: CRISES.

MARTES, Ana C. (2010), "Weber e Schumpeter: A ação econômica do empreendedor". Revista de Economia Política, v. 30, n. 2, pp. 254-270.

MCGOWAN, Katharine; WESTLEY, Frances. (2015), "At the Root of Change: The History of Social Innovation", in A. Nicholls, J. Simon; M. Gabriel (eds.), New frontiers in social innovation research. London, Palgrave/Macmillan UK, pp. 52-68.

MÉNDEZ, Ricardo. (2007), “Inovação localizada e eficiência coletiva: do território como suporte ao território como recurso para o desenvolvimento". In M. L. Maciel e S. Albagli (orgs.), Informação e desenvolvimento: conhecimento, inovação e apropriação social. Brasília, UNESCO/IBICT, pp. 247-269.

MENESES, João Wengorovius. (2010), “Liderança e Gestão das OSFL”. In: C. Azevedo; R. C. Franco; J. W. Meneses (coords.), Gestão de organizações sem fins lucrativos: o desafio da inovação social. Porto: Edições Vida Económica, pp. 135-161.

MONTEIRO, Alcides A. (2004), Associativismo e novos laços sociais. Coimbra, Quarteto.

. (2008), "Les initiatives de développement local au Portugal, entre la régulation et l'autonomie". RECMA - Revue Internationale de l'Économie Sociale, n. 309, pp. 64-75.

(2011), "Autonomia e co-responsabilidade ou o lugar da Educação de Adultos na luta pela inclusão social". Revista Lusófona de Educação, n. 19, pp. 67-83.

(2014), "The Active Role of Community-Based Organizations in the Local Redefinition of National Policies". Revista de Cercetare si Interventie Sociala, n. 46, pp. 203-215.

. (2015), "Espinafres, tartes de maçã e governança local”. Vez e Voz, Edição Especial - Março 2015, pp. 28-35.

MONTGOMERY, Tom (2016), "Are social innovation paradigms incommensurable?". Voluntas, v. 27, pp. 1979-2000.

MOULAERT, Frank et al. (2005), "Towards alternative model(s) of local innovation". Urban Studies, v. 42, n. 11, pp. 1969-1990.

MULGAN, Geoff. (2010), “Inovação Social”. in: C. Azevedo; R. C. Franco; J. W. Menezes (coords.), Gestão de organizações sem fins lucrativos: o desafio da inovação social. Porto, Edições Vida Económica, pp. 51-74.

et al. (2007), Social innovation: what it is, why it matters and how it can be accelerated. London, Young Foundation.

NILSSON, Warren; PADDOCK, Tana. (2014), "Social innovation from the inside out". Stanford Social Innovation Review, v. 12, n. 1, pp. 46-52. 


\section{Alcides Monteiro}

NUNES, Paulo. (2015), Conceito de externalidades [online]. Disponível em http://knoow. net/cienceconempr/economia/externalidades/. Acessado em 24 de setembro de 2016.

OECD (Organisation for Economic Co-operation and Development). (1997), Oslo manual: proposed guidelines for collecting and interpreting technological innovation data, OECD and European Commission. Disponível em http://www.oecd.org/dataoecd/35/61/2367580.pdf. Acessado em 23 de julho de 2016.

PHILLS Jr., James A.; DEIGLMEIER, Kriss; MILLER, Dale T. (2008), "Rediscovering social innovation". Stanford Social Innovation Review, v. 6, n. 4, 6.4, pp. 34-43.

RANCI, Costanzo; MONTAGNINI, Eugenia. (2008), The impact of comodification of social care on the role and identity of the third sector in Italy. paper presented at the CINEFOGO Workpackage 27, 14-15 de outubro, Berlin, Germany.

RICHEZ-BATTESTI, Nadine; PETRELLA, Francesca; VALLADE, Delphine. (2012), "Linnovation sociale, une notion aux usages pluriels: Quels enjeux et défis pour l'analyse?". Innovations, n. 38, pp. 15-36.

ROUSSELLE, Mylène. (2013), "L'innovation sociale, une solution durable aux défis sociaux". Informations Sociales, n. 180, pp. 140-148.

ROUSTANG, Guy. (2003), “Volatilité ou pérennité des innovations sociales de l'économie solidaire", Actes des 3ème Rencontres du Réseau Interuniversitaire d'Economie Sociale et Solidaire, Toulouse Le Mirail, 5 de março.

SANTOS, Filipe M. (2012), "A positive theory of social entrepreneurship". Journal of Business ethics, v. 111, n. 3, pp. 335-351.

SCHUMPETER, Joseph. A. (1926), Théorie de l'évolution économique. Paris, Dalloz.

SGMAP (Secrétariat-Général pour la Modernisation de l'Action Publique). (2015), Ensemble accélérons! Accompagner les acteurs de l'innovation dans leur changement d'échelle. Paris: Secrétariat Général pour la Modernisation de l'Action Publique.

SIBIEUDE, Thierry e CLAVERIE, Céline. (2011), La mesure de l'impact social - Après le temps des discours, voici venu le temps de l'action. Paris, Conseil Supérieur de l'Economie Sociale et Solidaire (CSESS).

SQUAZZONI, Flaminio. (2008),"Local economic development initiatives from the bottomup: the role of community development corporations". Community Development Journal, v. 44, n. 4, pp. 500-514.

SWEDBERG, Richard. (2000), "The social science view of entrepreneurship: introduction and practical applications". in: R. Swedberg (ed.), Entrepreneurship: the social science view. Oxford: Oxford University Press, pp. 7-44.

TORJMAN, Sherri; LEVITEN-REID, Eric. (2003), Innovation ad CED: What They Can Learn From Each Other. Ottawa, The Caledon Institute of Social Policy.

VALLAT, David. (2015), "Commons et innovation sociale". Communication au XVe Rencontres du RIUESS, Reims, 27-29 de maio. 
RESUMO

O que é a Inovação Social? Maleabilidade Conceitual e Implicações Práticas

Este artigo aborda uma realidade que, não sendo completamente nova, mereceu nos últimos anos particular atenção no que concerne à sua teorização e delimitação: o fenômeno (conceito e prática) da "inovação social". Na primeira parte, a análise focaliza a diversidade de concepções que se tem produzido em torno da definição da inovação social, conforme se olha o fenômeno como resposta a problemas sociais e a condições sociais, ou é primordialmente concebido no contexto da governança democrática e da vontade de transformação social. Por julgarmos possível, e desejável, entabular pontes entre modelos que, portadores de pressupostos importantes, se revelam incompletos na sua formulação própria, avançamos, na segunda parte do texto, com a proposta de um novo modelo estratégico para a inovação social local, que é distinto das duas concepções anteriores. Essa proposta é a de que se interprete o conceito de "inovação social", quando associado a uma estratégia de desenvolvimento local, como composto por dois eixos fundamentais: um eixo instrumental (inovações setoriais + governança e externalidades) e um eixo político (learning communities + missão social e visão transformadora). No âmbito de tal proposta, estimam-se ainda as implicações práticas decorrentes da adoção deste modelo.

Palavras-chave: inovação social; desenvolvimento local; missão social; democracia; transformação social

\section{ABSTRACT \\ What is Social Innovation? Conceptual Malleability and Practical Implications}

This article addresses a reality that, although not completely new, has drawn particular attention in the last years regarding its theorization and delimitation: the phenomenon (concept and practice) of "social innovation". In the first part, the analysis focuses on the diversity of conceptions around the definition of social innovation, perceiving this phenomenon as a response to social conditions and problems, or as primarily conceived in the context of democratic governance and the desire for social transformation. Since we think it is possible and desirable to build bridges between models that, caring important assumptions, are incomplete in their formulations, in the second part of the article we propose a new strategic model for local social innovation, which is distinct from the two previous conceptions. The proposal is to interpret the concept of "social innovation", when associated to a local development strategy, as composed of two fundamental axes: an instrumental axis (sectoral innovations + governance and 


\section{Alcides Monteiro}

externalities) and a political axis (learning communities + social mission and transforming vision). Within this proposal, the practical implications of adopting this model are also estimated.

Keywords: Social innovation; local development; social mission; democracy; social transformation

\section{RÉSUMÉ \\ Qu'est-ce que l'Innovation Sociale? Malléabilité Conceptuelle et Implications Pratiques}

Cet article aborde une réalité qui, bien que non tout à fait nouvelle, a mérité une attention particulière ces dernières années en ce qui concerne sa théorisation et sa délimitation: le phénomène (concept et pratique) de «l'innovation sociale». Dans la première partie, l'analyse met l'accent sur la diversité des conceptions élaborées autour de la définition de l'innovation sociale; le phénomène considéré comme une réponse aux problèmes sociaux et aux conditions sociales, ou conçu principalement dans le contexte de la gouvernance démocratique et du désir de transformation sociale. Puisque nous pensons qu'il est possible et souhaitable de créer des ponts entre des modèles dont la formulation est incomplète, avec des hypothèses importantes, nous avançons dans la deuxième partie du texte avec la proposition d'un nouveau modèle stratégique pour l'innovation sociale locale: distincte des deux conceptions précédentes. Cette proposition consiste à interpréter le concept «d'innovation sociale» (lorsqu'il est associé à une stratégie de développement local) tel que composé par deux axes fondamentaux: un axe instrumental (innovations sectorielles + gouvernance et externalités) et un axe politique (learning communities + mission sociale et vision transformatrice). Dans cette proposition, les implications pratiques de l'adoption de ce modèle sont également estimées.

Mots-clés: Innovation sociale; développement local; mission sociale; démocratie; transformation sociale 


\section{RESUMEN \\ ¿Qué es la Innovación Social? Maleabilidad Conceptual e Implicaciones Prácticas}

Este artículo aborda una realidad que, pese a que no es completamente nueva, mereció en los últimos años particular atención en lo que se refiere a su teorización y delimitación: el fenómeno (concepto y práctica) de la "innovación social". En la primera parte, el análisis se concentra en la diversidad de concepciones que se han producido alrededor de la definición de innovación social, conforme se observa el fenómeno como respuesta a problemas sociales y a condiciones sociales, o es primordialmente concebido en el contexto de la gobernanza democrática y de la voluntad de transformación social. Por considerar posible y deseable, establecer puentes entre modelos que, portadores de presupuestos importantes, se presentan como incompletos en su formulación propia, avanzamos, en la segunda parte del texto, con la propuesta de un nuevo modelo estratégico para la innovación social local, que es distinto de las dos concepciones anteriores. Esa propuesta es que se interprete el concepto de "innovación social", cuando se encuentra asociado a una estrategia de desarrollo local, como compuesto por dos ejes fundamentales: un eje instrumental (innovaciones sectoriales + gobernanza y externalidades) y un eje político (learning communities + misión social y visión transformadora). En el ámbito de dicha propuesta, se estiman además las implicaciones prácticas derivadas de la adopción de este modelo.

Palabras clave: innovación social; desarrollo local, misión social; democracia; transformación social 